\title{
Acoso sexista callejero: ¿qué respuesta puede ofrecer el Derecho penal? ( Sexist Street Harassment: What Kind of Answer Can the Penal Law Provide?)
}

\author{
Alicia Brox SÁENZ dE LA CALZADA*
}

\begin{abstract}
Brox Sáenz de la Calzada, A., 2019. Acoso sexista callejero: ¿qué respuesta puede ofrecer el Derecho penal? Received 04 J uly 2019, Accepted 16 September 2019. Oñati Socio-Legal Series [online], 9(6), 983-1000. Available from: https://doi.org/10.35295/osls.iis//0000$\underline{0000-0000-1080}$
\end{abstract}

\section{Resumen}

El presente trabajo analiza la polémica existente en el ámbito penal en torno a la creación de un delito de acoso sexista callejero. En un primer momento, se estudia el fenómeno en sí, sus repercusiones victimológicas y los problemas que plantea la falta de regulación penal al respecto, en el ámbito de la Comunidad Europea y en España. A continuación, ante una eventual reforma del sistema jurídico español, se comentan las posibilidades que ofrece el Derecho comparado belga y francés, países cuyos Códigos penales han sido reformados para sancionar este fenómeno. Ambas iniciativas, aunque bienintencionadas, corren el riesgo de convertirse en papel mojado.

\section{Palabras clave}

Derecho penal comparado; acoso sexista callejero; violencia contra las mujeres; género

\begin{abstract}
This paper analyses the controversy over the phenomenon of sexist street harassment under a legal perspective. Firstly, this paper studies the phenomenon itself, its impact on the victims and the problems caused by the lack of Spanish and European penal regulation. Secondly, considering a possible Spanish penal system reform, we discuss the options that Belgian and French comparative Law offers to tackle sexist street harassment. These two countries have reformed their Penal Codes to sanction this phenomenon. Both initiatives, though well-intentioned, run the risk of becoming waste paper.
\end{abstract}

Proyectos competitivos en cuyo marco se ha desarrollado el trabajo: El Tratamiento de la Violencia de Género en la Administración de Justicia. Implementación y eficacia de la LO 1/2004 (DER2014-55400-R); Grupo de Referencia Laboratorio de Sociología Jurídica (09_17R), del Gobierno de Aragón.

* Investigadora predoctoral F.P.U (Ayuda para la Formación de Profesorado Universitario, Ministerio de Educación y Cultura). Datos de contacto: Laboratorio de Sociología Jurídica, Área de Derecho Penal, Historia del Derecho y Filosofía del Derecho, Facultad de Derecho de la Universidad de Zaragoza, C/Pedro Cerbuna 12, 50009, Zaragoza. Dirección de email: abrox@unizar.es ORCID: https://orcid.org/0000-0001$\underline{5332-1009}$ 


\section{Key words}

Comparative criminal law; sexist street harassment; violence against women; gender 


\section{Í ndice / Table of contents}

1. Introducción ................................................................... 986

2. El desamparo frente al acoso sexista callejero y la necesidad de una respuesta jurídica............................................................................. 988

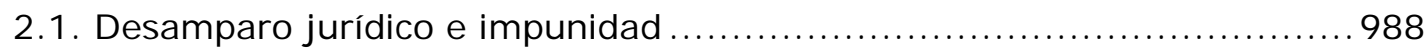

2.2. Una zona mal delimitada jurídicamente................................. 989

3. ¿Qué respuesta puede ofrecer el Derecho penal? ............................. 990

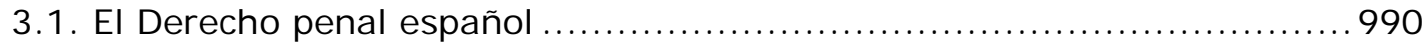

3.2. ¿Qué opciones ofrece el Derecho comparado? .......................... 992

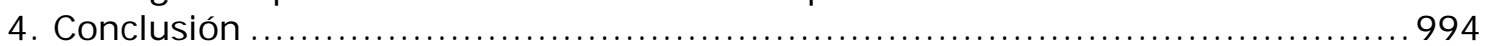

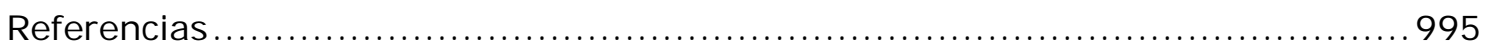

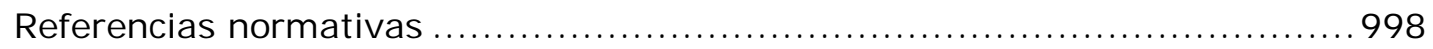


Most arguments against regulating street harassment are based on the idea that such regulations will stifle public discourse or interfere with dialogue between the sexes. These arguments presuppose an interchange free from coercion; however, as Catharine Mackinnon argues, 'rights to speak involve relations of power between private individuals'. Promoting the public speech rights of a particular group without recognizing these power relationships only facilitates the domination and silencing of women by men. Street harassment itself silences women, inhibits dialogue, and promotes sexual oppression. (Thompson 1993)

\section{I ntroducción}

El acoso sexista callejero, cuando se comete con una intención misógina, es una de las formas más frecuentes de violencia de género. Es, como precisa la Profesora Gil Ruiz (2013, p. 13), “un buen ejemplo de esa violencia que (...) padecen las mujeres en lo público, de su normalización por parte de quienes la ejercen, e incluso, lamentablemente, de quienes las soportan". En España, una de cada tres mujeres ha sufrido algún episodio de este tipo, ${ }^{1}$ y, según una encuesta reciente llevada a cabo por el Instituto IFOP (Clavaud et al. 2018) para la Fundación francesa Jean Jaurès, a lo largo de sus vidas, el $44 \%$ de las mujeres españolas encuestadas habría sido abordado en la calle de manera insistente, a pesar de haber manifestado su rechazo, un $86 \%$ habría sufrido algún silbido insistente y el $50 \%$ habría sido objeto de gestos groseros con connotación sexual. ${ }^{2}$ En este sentido, en un boletín mensual del Instituto Nacional de Estudios Demográficos Francés (en adelante, INED), se desvelaban datos alarmantes: en Francia, al año, en torno a tres millones de mujeres de entre 20 y 69 años habrían sido víctimas de algún tipo de flirteo inoportuno en el espacio público (Lebugle 2017, p. 13).

El acoso sexista callejero puede adoptar diversas formas, desde silbidos hasta "pellizcos, bofetadas, golpes, comentarios en voz alta, gestos vulgares, insultos, insinuaciones, miradas insistentes (...)" (Brooks 1995, p. 4), y, según el Informe elaborado por el Grupo de Trabajo Verbalización del acoso callejero, de la Secretaría de Estado Francés encargada de la igualdad entre las mujeres y los hombres, este problema, lejos de ser un fenómeno exclusivo de barrios populares, existe en todo el territorio nacional (Secretaría de Estado francés 2018, p. 13).

\footnotetext{
${ }^{1}$ Fuente: http://proyectocuentalo.org/\#numbers. Consultada el 26 de abril de 2019.

2 Datos obtenidos por el Instituto IFOP, en el Estudio realizado para la Fundación J ean J aurès y la Fundación europea de estudios progresistas, mediante cuestionario autoadministrado por internet, entre el 25 y el 30 de octubre de 2018, sobre una muestra de 6.025 mujeres, representativa de la población femenina mayor de 18 años, residente en Italia, España (muestra de 1.007 mujeres), Francia (muestra de 1.009), Alemania, Reino Unido y Estados Unidos. Ver el informe Les femmes face aux violences sexuelles et le harcèlement dans la rue (Clavaud et al. 2018). Ver, también, el estudio Sobre el acoso sexual y el acoso por razón de sexo en el ámbito laboral, elaborado en 2010 por la Fundación Mujeres, Ministerio de I gualdad, en el en el marco del Proyecto Servicio de apoyo al diseño y ejecución de Planes de igualdad en las empresas La Profesora Juana María Gil Ruiz comenta que "en el estudio editado recientemente por el Ministerio de Igualdad, en 2010, sobre el acoso sexual y el acoso por razón de sexo en el ámbito laboral, se recoge como dato significativo el reducido índice de denuncias registrado. El estudio señala como factores que limitan la visualización y denuncia de estas situaciones, la dificultad para definir la naturaleza de lo que constituye acoso sexual y acoso por razón de sexo, dado que el sistema de creencias sexistas que aún perdura en la sociedad española normaliza este tipo de conductas. Las percepciones sociales de lo que es esperable de los hombres en sus relaciones con las mujeres lleva a calificar como simple interés o mero galanteo lo que son situaciones de acoso sexual o acoso por razón de sexo según la normativa vigente. Las víctimas tienen tan normalizadas ciertas conductas violentas que se contentan con aceptar que forman parte de las reglas del juego entre los sexos. En otros casos rechazan interponer una denuncia al valorar la animadversión que en la empresa se generaría contra ellas por atreverse a hacer públicas este tipo de conductas. Pero igualmente sorprende en el estudio, que el silencio de la acosada ante agresiones anteriores quite valor y coherencia a su palabra, debiendo justificar ante la empresa o ante la administración y, más tarde, durante el proceso, por qué motivo ahora denuncia y antes no (...)" (Gil Ruiz 2013, p. 13).
} 
Algunas voces feministas (Farley 1978, Siegel 2003) reivindican públicamente desde los años 1980 una respuesta penal para el acoso sexual, ${ }^{3}$ ya que sería una de las muchas caras de la violencia ejercida contra las mujeres de las que el Estado debería hacerse cargo para garantizar la plena eficacia del derecho a la ciudadanía.

Con respecto al acoso sexista callejero, tal y como señala Tapia Ballesteros (2016, p. 36), "no es posible llevar a cabo un estudio (...) sin tener presente el acoso sexual", puesto que "las primeras acciones de reivindicación y de reconocimiento del acoso como una conducta no deseable y merecedora de reproche social y jurídico, se limitan a una categoría concreta: el acoso sexual en el ámbito laboral". En este sentido, la Profesora Barrère Unzueta precisa que "Ios primeros pasos relativos a la teorización del tipo de prácticas como las mencionadas se producen por obra de activistas y juristas feministas estadounidenses, y se insertan en un contexto desencadenado por la lucha por los derechos civiles en este país que da origen al moderno derecho antidiscriminatorio" (Barrère Unzueta 2013, pp. 18 y 19). "Las primeras teorías sobre el acoso sexual en los Estados Unidos emergen de las propias experiencias de las mujeres" (Saguy 2000, p. 1101), en particular, gracias a un grupo de autoconciencia (consciousness-raising group), dirigido por Lin Farley en 1974 (Farley 1978).

No obstante, dar forma jurídica a dichas teorías es una ardua tarea que plantea varias dificultades técnicas. El carácter polimórfico de este problema complica la respuesta punitiva, ya que los comportamientos en cuestión poseen características de varias infracciones a la vez, sin llegar a corresponder a ninguna en sentido estricto. Se trata, en efecto, de una zona gris del Derecho, mal delimitada jurídicamente y cuya sanción no siempre es efectiva, debido también a los grandes problemas que conlleva la falta de elementos de prueba.

Los acontecimientos de finales del año 2017, como el caso Weinstein (El País 2019) el consiguiente movimiento \#MeToo (Ximenez 2018) y la respuesta a la polémica Carta de las 100 (Vicente 2018) reflejan una mayor toma de conciencia social sobre la existencia y magnitud del problema del acoso sexista en general, entre cuyas modalidades se encuentra el callejero. Además, con la ratificación por varios países del Convenio del Consejo de Europa sobre prevención y lucha contra la violencia contra las mujeres y la violencia doméstica ${ }^{4}$ (en adelante, CE) (España lo hizo el 10 de abril de 2014), la cuestión ha cobrado mayor relevancia en las agendas políticas, y varios Estados miembros de la Unión Europea ya han tomado medidas al respecto, codificando nuevas figuras penales específicas. En España, la legislación penal todavía no contempla el acoso sexista callejero, aunque sí el stalking y el tipificado acoso sexual.

Así las cosas, la ratificación del reciente Pacto de Estado contra la Violencia de Género en España (Secretaría de Estado español de Igualdad 2017) ha favorecido la elaboración de una Proposición de Ley de Protección Integral de la Libertad Sexual y para la Erradicación de las Violencias Sexuales ${ }^{5}$ (Proposición de Ley no 122/000279). Presentada el pasado 2 de octubre de 2018 por el Grupo Parlamentario Confederal Unidos Podemos-En Comú Podem-En Marea, su objetivo, entre otras muchas cosas, consistía en la creación de un delito leve de acoso en la vía pública, también llamado "acoso sexual callejero". La iniciativa ha suscitado tanta curiosidad como polémica, ya que, al ser difícil de probar, el delito corre el riesgo de no ser sancionado. Además,

\footnotetext{
${ }^{3}$ Ver, entre otros, los trabajos realizados por las juristas Lin Farley, Rieva Siegel y Catharine MacKinnon en los años 1970. "In the 1970s Catharine MacKinnon and Lin Farley and the many other lawyers and activists who represented women in and out of court were able to mount a concerted assault, of unprecedented magnitude and force, on the practice of sexual harassment. Responding on many fronts to the demands of the second-wave feminist movement, the American legal system began slowly to yield to this challenge, and for the first time recognized women's right to work free of unwanted sexual advances" (Siegel 2003, p. 8).

${ }^{4}$ También Ilamado "Convenio de Estambul". El texto internacional insta a los países signatarios a introducir la perspectiva de género en las legislaciones sobre violencia de género y violencia intrafamiliar y a considerar la primera en su sentido más amplio.

${ }^{5}$ La Proposición de Ley en cuestión caducó con el cambio de Legislatura.
} 
una vez legislado, sucede que muchas mujeres que lo sufren no lo denuncian porque desconocen la existencia de una respuesta punitiva. De este modo, la creación de una nueva figura delictual podría, sin duda, paliar la insuficiencia normativa, pero también se corre el riesgo de que el dispositivo se convierta en una suerte de Derecho penal simbólico, como parece ser el caso de Francia o de Bélgica, países que prevén una sanción penal para este tipo de acoso pero cuya eficacia real es muy limitada. Por ejemplo, en 2015, Bruselas capital tan solo registró tres denuncias por acoso sexista (Secretaría de Estado francés 2018, p. 16). Si, en la práctica, y a la luz del derecho comparado, el delito de acoso sexista callejero no surte la eficacia prevista, ¿es necesario recurrir al Derecho penal para tratar este problema? En caso de que así sea, ¿qué respuesta puede ofrece dicho Derecho? Con independencia de las consecuencias psicológicas que causa en el desarrollo y en la conducta de las personas que lo sufren, la cuestión que se plantea en Derecho consiste en saber en qué medida el acoso sexista callejero justifica una respuesta punitiva específica. Es decir, debemos plantearnos en qué medida la repercusión jurídica de este problema es mayor que la puedan llegar a tener algunos comportamientos incívicos que no reciben ningún tratamiento penal específico (Bowman 1993).

\section{El desamparo frente al acoso sexista callejero y la necesidad de una respuesta jurídica}

\subsection{Desamparo jurídico e impunidad}

En 2014, un documento oficial de las Naciones Unidas sobre el acoso callejero declaraba que "pese a que actualmente la violencia en el ámbito privado se reconoce ampliamente como una violación de derechos humanos, la violencia contra mujeres y niñas, en especial el acoso sexual en espacios públicos, sigue siendo un tema en gran medida desatendido, con pocas leyes o políticas para acometerla y prevenirla" (ONU Mujeres 2014). Dicho desinterés es todavía más relevante en lo que atañe al acoso sexista callejero cometido por hombres sobre mujeres, frecuentemente banalizado (Brooks 1995, p. 9).

Además, las víctimas de violencia de género suelen vivir las consecuencias en silencio, lo cual sucede todavía con mayor frecuencia cuando se trata de este tipo de acoso sancionado en pocos países. Como apuntábamos, en la Unión Europea, tan solo tres Estados (Bélgica, Portugal y Francia) cuentan con una regulación penal específica. ${ }^{6}$ Bélgica fue uno de los primeros en tenerla, gracias, en parte, a la repercusión que tuvo el documental Femme de la Rue (2012) de Sofie Peeters en 2014. Un año más tarde, Portugal aprobaba la creación de un delito de "importunación sexual" (importunação sexual) en el artículo 170 de su Código penal; ${ }^{7}$ $y$, muy recientemente, Francia, ha incluido una contravención de "ultraje sexista" (outrage sexiste) en el artículo 621-1 de su ley penal. ${ }^{8} \mathrm{~A}$ pesar de que, en la Unión Europea, entre el $45 \%$ y el $55 \%$ de las mujeres ha experimentado alguna forma de acoso sexista desde los 15 años de edad, a día de hoy, la falta de regulación específica causa un gran desamparo legal. Contra esta impunidad intentan luchar iniciativas

\footnotetext{
6 Desde julio de 2016, el Condado de Nottinghamshire, en Reino Unido, permite sancionar los comportamientos sexistas como hate crimes (Brooks 2018).

${ }^{7}$ El artículo 170 del Código penal portugués se codificó mediante la Ley 83/2015 de 5 de agosto, Trigésima oitava alteração ao Código penal, aprovado pelo Decreto-Lei n. 400/82, de 23 de setembro, autonomizando o crime de mutilação genital feminina, criando os crimes de perseguição e casamento forçado e alterando os crimes de violação, coação sexual e importunação sexual, em cumprimento do disposto na Convenção de Istambul.

8 Infracción codificada a través de la Ley francesa no 2018-703 del 3 de agosto de 2018, titulada Loi renforçant la lutte contre les violences sexuelles et sexistes. Ver, en concreto, el artículo 621-1 del Código penal francés, en el que se define el acoso callejero como el "hecho de imponer a una persona cualquier comentario o comportamiento con connotación sexual o sexista que, o bien atente contra su dignidad en razón de su carácter degradante o humillante, o bien cree una situación intimidatoria, hostil u ofensiva en su contra".
} 
como Hollaback (www.ihollaback.org), Stop Street Harassment (www.stopstreetharassment.org) 0 Stop Harcèlement de Rue (www.stopharcelementderue.org/quest-ce-que-le-harcelement-de-rue/) así como los varios proyectos que se han lanzado a nivel comunitario y estatal para medir el impacto del acoso sexista callejero a lo largo de los últimos cinco años. ${ }^{9} \mathrm{~A}$ pesar de todo, el fenómeno rara vez desencadena una respuesta punitiva que vaya más allá de la sensibilización. ¿Por qué?

\subsection{Una zona mal delimitada jurídicamente}

Reprimir penalmente el acoso sexista callejero plantea varias cuestiones jurídicas. Sin pecar de prurito punitivista, ¿es posible recurrir a un Derecho que, técnicamente es de ultima ratio, para sancionar comportamientos que, a priori, pueden parecer meramente incívicos o molestos?

Como hemos venido diciendo, dicho acoso se puede manifestar de formas muy distintas, que, en algunas ocasiones, constituyen una infracción ya tipificada, y, en otras, poseen elementos característicos de varios delitos, sin llegar a corresponder plenamente a ninguno en particular. Por ejemplo, un insulto de carácter misógino podría caracterizar una injuria. Pero ¿qué sucede si lo que se verbaliza no es un improperio sino un piropo fuera de lugar, inoportuno e inadecuado? ¿Es apropiado recurrir al Derecho penal en estos casos? ¿Es posible sancionar estos actos sin limitar mínimamente la libertad de expresión?

Además de los problemas que plantea delimitar conceptualmente el acoso sexista, cuando éste sí se sanciona, las víctimas se enfrentan a dificultades probatorias, porque los medios son normalmente escasos. La falta de testimonios y de elementos de prueba, son solo algunos de los varios inconvenientes que conlleva crear una figura penal para reprimir este tipo de violencia, ya que, cuando no queda rastro de ninguna lesión aparente, ni existen testigos que presencien el comentario, silbido, o seguimiento, la denuncia parece de dudosa eficacia. Por otro lado, cuando el acoso consiste en una injuria puntual de carácter sexista, y la persona que lo comete se aleja de la zona donde lo ha verbalizado, es poco probable que vaya a ser identificado.

Frente a estas complicaciones, algunos países han optado por formar agentes de Policía para que puedan velar por la seguridad de las víctimas en lugares públicos, y, en determinados casos, multen in situ a los acosadores. Pero, de nuevo, estas medidas tampoco garantizan la plena eficacia de la respuesta punitiva, porque no es habitual que los agresores actúen delante de las fuerzas de seguridad.

A pesar de estar presente en la vida de muchas mujeres, el acoso sexista callejero es una realidad que queda fácilmente impune. Sus secuelas psicológicas no son nada desdeñables: varios estudios académicos, demuestran que, a raíz del miedo y de la situación de inseguridad que provocan las agresiones, las mujeres padecen episodios de ansiedad, a causa de los cuales deciden adoptar estrategias para pasar desapercibidas y evitar frecuentar determinados lugares (Thompson 1993, Lieber 2002, Condon et al. 2005, Bodelón 2014, p. 15). Todo ello limita la autonomía, la libre circulación en los espacios públicos, vulnera, aunque sea mínimamente, el derecho a la seguridad personal, a la privacidad, a la integridad, y, en definitiva, merma el desarrollo y el goce efectivo de la ciudadanía. Siguiendo a Calvo (2014, p. 199, 2016) y a Bowman (1993, p. 517), creemos que parte de los vacíos legales que genera el acoso callejero podrían solucionarse, al menos parcialmente, si, jurídicamente, se asumiera como un problema que vulnera derechos fundamentales. Ello contribuiría a mitigar el sentimiento de inseguridad y a reafirmar la neutralidad del espacio público. "Afrontar la violencia de género con el objetivo de erradicarla

\footnotetext{
${ }^{9}$ Ver, por ejemplo, en Francia, el Plan Nacional de 2015 de Lucha contra el Acoso Sexista y las Violencias Sexuales (Ministerio francés del Interior 2015), o la campaña de sensibilización en los transportes públicos de la región parisina (RATP 2018). En España, la J unta de Andalucía también lanzó en 2017 una campaña contra dicho acoso bajo el lema No seas animal.
} 
requiere un paso más: dar entrada a los derechos de la mujer y plantear la intervención desde objetivos que busquen políticas transformadoras de las relaciones sociales para acabar con las discriminaciones y asimetrías de poder que alientan la violencia de género" (Calvo 2014, p. 199).

\section{3. ¿Qué respuesta puede ofrecer el Derecho penal?}

\subsection{El Derecho penal español}

El Derecho penal español prevé dos figuras que cubren ciertos tipos de acoso: ${ }^{10}$ el stalking y el acoso sexual. ${ }^{11}$ No dice nada sin embargo del que se realiza de manera puntual, con ánimo sexista, en la vía pública. ${ }^{12}$

Con respecto al stalking, ${ }^{13}$ regulado en el artículo 172.ter del Código penal español (en adelante CPE), tipificado gracias al CE e implementado mediante la Ley Orgánica 1/2015 de 30 de marzo, por la que se modifica la Ley Orgánica 10/1995, de 23 de noviembre, del Código penal (B.O.E n. 77 de 31.03.2017), la figura delictual podría contemplar algunos casos de acoso sexista callejero, en la medida en que prevé una sanción para el "que acose a una persona llevando a cabo de forma insistente y reiterada, y sin estar legítimamente autorizado, alguna de las conductas siguientes $y$, de este modo, altere gravemente el desarrollo de su vida cotidiana: la vigile, la persiga o busque su cercanía física (...) atente contra su libertad o contra su patrimonio, o contra la libertad o patrimonio de otra persona próxima a ella". Sin embargo, al exigir que los comportamientos en cuestión se cometan "de forma insistente y reiterada" y alteren "gravemente el desarrollo de [la] vida cotidiana" de la víctima, limitando su capacidad de obrar, el stalking solo permitiría sancionar los casos de acoso sexista callejero más graves (art.172.ter CPE). En efecto, como precisa Tapia Ballesteros, "la exigencia de que una conducta sea insistente y reiterada, para que se califique de acosadora, significa que el actuar aislado o la realización de una conducta casual de vigilancia, persecución o búsqueda de acercamiento físico, de tratar de establecer contacto, o lograrlo, a través de un medio de comunicación o por terceras personas (...), no es relevante penalmente, resulta atípica" (Tapia Ballesteros 2016, p.145).

Por otro lado, desde 1995, el Código penal español hace mención del acoso sexual en su artículo 184, sancionando al "que solicitare favores de naturaleza sexual, para sí o para un tercero, en el ámbito de una relación laboral, docente o de prestación de servicios, continuada o habitual, y con tal comportamiento provocare a la víctima una situación objetiva y gravemente intimidatoria, hostil o humillante". En opinión de Daza Bonachela, "el objetivo principal de esta tipificación expresa del acoso sexual era resolver un problema de inaplicación de la ley, no tanto de falta de norma aplicable. Las violencias contra las mujeres, entre ellas el acoso sexual, podían

${ }^{10}$ El Código penal prevé también otros tipos de acoso, como el laboral (art. 173.1, 1ํ), el inmobiliario $\left(173.1,2^{\circ}\right.$ ) o el sexual cibernético sobre menores (art. 183.ter), pero en este artículo solo se estudiarán el sexual y el stalking porque, a nuestro parecer, son los únicos que potencialmente pueden llegar a aplicarse en algunos casos de acoso sexista callejero.

${ }^{11}$ El artículo 7 de la Ley Orgánica 3/2007 para la Igualdad Efectiva entre Hombres y Mujeres vino a precisar que dicho acoso es un acto "discriminatorio".

${ }_{12}$ No obstante, algunos textos legales fuera del ámbito penal sí parecen mencionarlo. El citado artículo 7 de la LO 3/2007 define ampliamente el acoso sexual y el acoso por razones de sexo, de los que se podría entender que el acoso callejero es una de sus modalidades, ya que entiende el primero "cualquier comportamiento, verbal o físico, de naturaleza sexual que tenga el propósito o produzca el efecto de atentar contra la dignidad de una persona, en particular cuando se crea un entorno intimidatorio, degradante u ofensivo; $y$, el segundo, como "cualquier comportamiento realizado en función del sexo de una persona, con el propósito o el efecto de atentar contra su dignidad y de crear un entorno intimidatorio, degradante u ofensivo". Para un análisis de las dificultades conceptuales que existen entre el ya tipificado "acoso sexual" y la figura del acoso "por razón de sexo" modificada a través de la LO 3/2007, ver Rubio Castro 2013.

13 Para un estudio detallado de esta nueva figura delictual, ver Rivas Vallejo y García Valverde 2015 y Tapia Ballesteros 2016. 
castigarse por otras vías comunes (...), pero no se castigaban" (Daza Bonachela 2012, p. 79). Tapia Ballesteros entiende que, con este delito, "el legislador pretendía dar respuesta a una reivindicación proveniente especialmente de sectores feministas. No obstante, la concreta regulación no resultó satisfactoria para estos, y, además, fue duramente criticada por la doctrina penal". ${ }^{14}$ En efecto, "la previsión del artículo 184 era insuficiente por la limitación establecida tanto en el ámbito objetivo de aplicación como del subjetivo" (Tapia Ballesteros 2016, p. 65). Al exigir la existencia de una "relación laboral, docente o de prestación de servicios" entre agresor y víctima, quedan excluidos los casos de acoso sexual cometidos por personas desconocidas. Dado que, en situaciones de acoso sexista callejero, lo habitual es que entre acosador y víctima no exista ningún vínculo relacional, el artículo 184 del CPE solo cubriría algunos casos puntuales. Pero, además, según el texto legal, la relación entre sujeto acosado y persona que acosa ha de ser "continuada o habitual", así que los episodios de acoso fugaces o esporádicos - frecuentes en los casos de acoso callejero- también quedan fuera del ámbito de aplicación del delito en cuestión (Lamarca Pérez 2010, p. 165).

Con todo, España ratificó el CE el 1 de abril de 2014, entrando en vigor en agosto de ese mismo año. Desde entonces, el texto vincula a los Estados signatarios a sancionar las formas de violencia de género previstas, e invita a incluir la perspectiva de género en las legislaciones y medidas de prevención. En este sentido, el citado texto define el acoso sexual ${ }^{15}$ de manera bastante más amplia que el Derecho interno, sin exigir los actos reiterados o la existencia de una relación profesional entre acosador y sujeto acosado. El artículo 40 del CE determina, en efecto, que es acoso sexual "toda forma de comportamiento no deseado, verbal, no verbal o físico, de carácter sexual, que tenga por objeto o resultado violar la dignidad de una persona, en particular cuando dicho comportamiento cree un ambiente intimidatorio, hostil, degradante, humillante u ofensivo". Del texto del CE se desprende que el acoso callejero puede incluirse en la definición genérica del acoso sexual. Además, como acabamos de ver, mediante la ratificación del texto, España se ha comprometido a sancionar todas las formas de violencia de género que figuran en él.

Prueba de dicho compromiso es el reciente Pacto de Estado contra la Violencia de Género, que resulta de la implementación del $C E$, y que menciona que, en la Macroencuesta de la Delegación del Gobierno para la violencia de género, se incluirán "nuevos baremos e indicadores", "con especial atención al llamado acoso callejero" (Secretaría de Estado español de igualdad 2017, medida no 258). Además, la citada Proposición de Ley, entregada el pasado octubre de 2018 por el Grupo Confederal En Común-Podemos, preveía, explícitamente, la creación de un delito leve de acoso callejero. En efecto, según el artículo 45 del texto, se incluiría "un nuevo artículo 172 quater en el Código penal, que queda[ría] redactado de la forma siguiente: Será castigado con pena de multa de tres a nueve meses o trabajos en beneficio de la comunidad de 31 a 50 días el que se dirija a una persona en la vía pública con proposiciones, comportamientos o presiones de carácter sexual o sexista que, sin llegar a constituir trato degradante ni atentado contra la libertad sexual, creen para la víctima una situación intimidatoria".

No obstante, como se ha sugerido anteriormente, a menos que existan testigos, o que la víctima grabe los actos, es difícil iniciar un procedimiento judicial por acoso. Por eso, para una correcta implementación del dispositivo, es necesaria la dotación de medios económicos suficientes, y la realización de un importante esfuerzo para formar agentes de Policía en temas de discriminación de género y de acoso sexista. Esto es precisamente lo que han hecho algunos países que ya cuentan con una legislación penal al respecto. Así, Francia, para paliar las dificultades probatorias a

\footnotetext{
${ }^{14}$ Ver, por ejemplo, un primer artículo de Larrauri Pijoán 1997, p. 182.

${ }^{15}$ El texto del CE prevé dos tipos de acoso. Por un lado, el artículo 34 menciona el "acoso", para el que exige comportamientos reiterados, y, por otro, en el artículo 40 figura el "acoso sexual", para el que no se precisa dicha reiteración.
} 
las que han de hacer frente las víctimas al denunciar los acosos, ha optado por instruir a agentes de la Policía Judicial, que pueden multar in situ a los agresores.

\section{2. ¿Qué opciones ofrece el Derecho comparado?}

\subsubsection{El Derecho penal francés: una contravención de ultraje sexista}

En octubre de 2017, el caso Weinstein estallaba en Estados Unidos, provocando una ola de denuncias públicas que se hizo rápidamente viral. El eco del escándalo llegó a varios países europeos mediante plataformas creadas en las redes sociales. En Francia, el movimiento se organizó gracias al hashtag \#BalancetonPorc (versión francesa del \#Metoo), mediante el que mujeres de todo el país denunciaron públicamente sus experiencias de acoso, fundamentalmente sexual, pero también callejero. La repercusión jurídica de este fenómeno se tradujo en un notable aumento de denuncias (ver la encuesta Insécurité et délinquance de 2017; Ministerio francés del Interior 2018) frente al que la respuesta institucional no se hizo esperar: Marlène Schiappa, secretaria de Estado por la I gualdad entre Hombres y Mujeres, anunció en 2018 la intención de crear una Ley para reforzar la lucha contra las violencias sexuales y sexistas. Después de un largo debate, la Ley en cuestión se promulgó en agosto de 2018 (Ley francesa $n^{\circ}$ 2018-703). ${ }^{16}$ Entre las modificaciones aportadas, se codificó una contravención de ultraje o acoso sexista, con la que se sancionan los comentarios y/o comportamientos con connotación sexual o sexista y que, independientemente del lugar en el que se expresen, o la forma en la que se manifiesten, atenten contra la dignidad de la persona en razón de su carácter degradante o humillante, o bien generen una situación intimidatoria, hostil u ofensiva (Nuevo artículo 621-1 del Código penal francés). A diferencia del acoso sexual previsto en el artículo 222-33 del Código penal galo, para caracterizar la contravención, ni se exige que dichos comportamientos sean reiterados, ni es imprescindible la denuncia del agraviado.

En una Circular del 3 de septiembre de 2018, Nicole Belloubet, actual ministra francesa de Justicia precisaba que podrían ser calificados como actos de ultraje sexista: "Ias propuestas sexuales", las "actitudes no verbales como gestos que imiten o sugieran un acto sexual, silbidos o ruidos obscenos cuya finalidad sea interpelar a la víctima de manera degradante" y los "comentarios degradantes sobre la actitud indumentaria" (Ministerio francés de Justicia 2018). El texto añadía que la prueba de los hechos podría ser aportada mediante testimonios o medios de video proyección, en un procedimiento judicial clásico o mediante atestado policial electrónico (verbalisation par procès-verbal éléctronique) (Asamblea Nacional francesa 2018) realizado in situ por los agentes de Policía Municipal, y/o por aquellos encargados de la seguridad en los transportes públicos. Dicha verbalización no excluye el procedimiento mediante denuncia clásica, con fase de instrucción y decisión judicial, pero, según el Informe precitado del Grupo de Trabajo Verbalización del acoso callejero, "aunque la víctima no denuncie, el acoso sexista en el espacio público, al igual que otros hechos que dan lugar a atestado policial sin denuncia, constituye una alteración del orden público que conviene sancionar" (Secretaría de Estado francés 2018, p. 21).

En cierta medida, esta ampliación de competencias a favor de la Policía garantiza una mayor efectividad del dispositivo penal, porque favorece, a priori, su aplicación, pero exige, seguramente, un aumento de la presencia policial, lo que inevitablemente provoca una incómoda sensación de punitivismo legal y cuestiona los principios de intervención mínima ${ }^{17}$ y de estricta necesidad del Derecho penal. En este sentido, Saas (2018) estima que el derecho positivo previo a la creación de dicha infracción

\footnotetext{
16 También Ilamada "Ley Schiappa”, en honor a la a la secretaria de Estado francesa por la Igualdad entre Mujeres y Hombres (en funciones desde mayo de 2017).

${ }^{17}$ La introducción de la infracción de ultraje sexista ha generado un polémico debate en el mundo doctrinal (Darsonville 2017, pp. 532-534, Planque 2017).
} 
ya permitía sancionar estos hechos gracias al delito de acoso sexual, porque su regulación no excluía de su ámbito de aplicación el espacio público.

A pesar de ello, la reforma ha supuesto un cierto avance, ya que "la existencia de dicha infracción permite (...) imponer una prohibición clara, cuyo significado implica que los comportamientos citados ya no son meros actos incívicos tolerados, sino que pertenecen al ámbito penal" (Asamblea Nacional francesa 2018, p. 53). Además, se han implementado diversos medios de prevención y concienciación, entre ellos, la formación específica que reciben los agentes de Policía Judicial y Municipal y los de Seguridad de los Transportes Públicos, competentes para multar in situ (art. 21, Código procesal penal francés, y art. L2241-1, Código francés de los transportes) Con todo, la apreciación por parte de los agentes en cuestión también puede comportar algún inconveniente, porque a la hora de realizar el atestado, la facultad de determinar el carácter denigrante o humillante del comportamiento con connotación sexual o sexista, o la situación intimidatoria, hostil y ofensiva, va a depender de ellos. Si la formación recibida es insuficiente, y el agente banaliza la situación de acoso, el dispositivo causará más problemas de los que podría resolver (Denizot y Mallet-Bricout 2018). Por ejemplo, cuando la intención del acosador no queda suficientemente clara a ojos de un agente poco avezado, ¿cómo se puede calificar una mirada o un silbido insistente? Un cumplido podría generar una situación de incomodidad, susceptible de sanción según la ley, pero eso requeriría cierto grado de concienciación por parte de los funcionarios en una cuestión discrecional. Por eso, como precisa la Profesora Tellier-Cayrol (2018), ante comportamientos medianamente ambiguos, "la interpretación de los comentarios requiere solicitar la opinión de la víctima", consideración que, según los principios rectores del Derecho penal, no debería ser determinante, aunque sí puede ser relevante.

A pesar de la loable intención que persigue la reforma, por ahora, la contravención francesa solo ha dado lugar a una condena. Como sucede con el modelo belga, la dificultad que supone recoger pruebas merma su eficacia.

\subsubsection{El delito de "sexismo ordinario" sancionado por el Derecho penal belga}

El 26 de julio de 2012, Bélgica difundía en la cadena de televisión Canvas el documental Femme de la Rue, de Sofie Peeters, estudiante de audiovisuales que grababa el acoso sexual callejero que sufría mientras paseaba por distintas calles de Bruselas. La emisión causó gran conmoción en la sociedad y en el Parlamento belga, cuya respuesta fue la creación de un delito general de "sexismo", mediante la Ley de 22 de mayo de 2014, Ilamada Loi tendant à lutter contre le sexisme dans l'espace public et modifiant la loi du 10 mai 2007 tendant à lutter contre la discrimination entre les femmes et les hommes afin de pénaliser l'acte de discrimination (M.B $\mathrm{n}$. 55452 de 24.07.2014) (en adelante, LB). Con él, se sanciona mediante una "pena de un mes a un año de cárcel y/o mediante una multa de 50 a 1.000 euros" a todo aquel que, en público o ante testigos, exprese, a través de gestos o actos "un desprecio hacia la víctima, en razón de su pertenencia sexual, o la considere inferior o reducida esencialmente a su dimensión sexual de manera que conlleve un grave atentado a su dignidad" (LB, art. 2).

A pesar de la desproporción que existe entre las penas de prisión que contempla el texto y los hechos jurídicamente reprochables, el dispositivo en sí ha aportado ciertos beneficios en la lucha contra el sexismo. En primer lugar, como en el caso francés, los distintos cuerpos policiales reciben formación sobre acoso sexual y sexista, organizada por parte del organismo competente en materia de igualdad de oportunidades $^{18}$ y por diversas asociaciones, entre ellas, TouchePasAMaPote (www.touchepasamapote.be), que también organiza sesiones de sensibilización para estudiantes. Los talleres en cuestión han mejorado los niveles de detección y han contribuido a una mejor comprensión y recogida de datos en las denuncias. Un

18 Desde julio de 2019, el cargo de Secretaria de Estado para la I gualdad de Oportunidades en el Gobierno de Bruselas Capital es desempeñado por Nawal Ben Hamou (PS). 
segundo aporte de la Ley ha sido la creación de una aplicación telefónica que permite geolocalizar las agresiones y detectarlas con mayor celeridad. Por último, también cabe mencionar que el ámbito de aplicación de la infracción es suficientemente amplio como para cubrir un gran elenco de posibilidades, contribuyendo así a un Derecho penal más garantista para las víctimas.

Pese a ello, lo cierto es que, como desvela el estudio realizado por JUMP en 2016, empresa social europea, si, en Bélgica, más de nueve mujeres sobre diez ya han sido víctimas de comportamientos sexistas "en espacios públicos, en particular en la calle o en medios de transporte", las que denuncian son pocas, porque muchas desconocen la Ley o temen que la Policía desconfíe de sus relatos (J UMP 2016). De hecho, aunque el texto en cuestión entró en vigor en 2014 , la primera condena no se dictó hasta 2018. ${ }^{19}$ Los detractores afirman que es un dispositivo ineficaz, cuya razón de ser es "más política que legal" (Charruau 2015). En 2015 solo se habían registrado tres denuncias por acoso sexista, y todas ellas habían sido archivadas por falta de pruebas (Vandekerkhove 2018).

\section{Conclusión}

Aunque el reformismo legal de los últimos veinte años ha contribuido a luchar contra la violencia de género mediante la elaboración de un complejo entramado jurídico (Calvo 2014, p.199), todavía quedan manifestaciones de esta lacra que los códigos penales ignoran, como es el caso del acoso sexista callejero, forma de violencia de género que pocos países europeos sancionan penalmente. Los recientes acontecimientos en torno al movimiento \#MeToo reflejan la necesidad de aportar una respuesta jurídica adecuada.

Para salvar estos vacíos legales, en España, la citada Proposición de Ley de Protección Integral de la Libertad Sexual y para la Erradicación de las Violencias Sexuales propuso crear un delito leve que sancionara el acoso sexista callejero. En cierta medida, esta iniciativa planteaba un debate social que permitía "dejar huella, tanto simbólica (la lucha contra el sexismo es igual de importante que la lucha contra el racismo o la homofobia), como política (dicha lucha se concretiza mediante un compromiso formal de los poderes públicos), y educativa (las discusiones ayudan a una toma de conciencia colectiva)" (Mallaval 2017, citando a Charruau 2015). ${ }^{20}$ Sin embargo, tal y como se percibe a través del modelo belga, su aplicación práctica es de dudosa eficacia. Tipificar un delito cuyas dificultades probatorias pueden llegar a mermar su aplicación, llevando a las víctimas a desistir de la denuncia, acabaría por desvirtuar la capacidad transformadora del Derecho. Para evitar que así sea, convendría, más que poner el foco de atención en la función punitiva del Derecho penal, seguir incrementando las medidas de prevención primaria, como la formación de los agentes de Policía y de Seguridad, para que, en los casos menos graves, pudieran interpelar a los acosadores sorprendidos en el acto, sin ser necesariamente multados, mejorando así los niveles de detección. También sería necesario hacer de la ciudad y de los espacios públicos lugares inclusivos, adaptados a la diversidad, mediante estudios exploratorios que tuvieran en cuenta la opinión de las mujeres a la hora de repensar las estructuras institucionales, así como abrir el público al que se dirigen los talleres educativos de formación contra la violencia de género, dotando de un mayor presupuesto las iniciativas de promoción y difusión de campañas publicitarias acerca de este fenómeno. En definitiva, convendría replantear el tratamiento jurídico del acoso sexista callejero bajo una óptica más didáctico-

\footnotetext{
19 Además, en este caso, la víctima era una agente de Policía a la que un hombre, a quien ella estaba multando por cometer una infracción al volante, insultó y contestó que debería "buscarse un trabajo adaptado a las mujeres".

20 "Cela peut présenter un intérêt, par le débat de société qu'il crée, de laisser une trace tout à la fois symbolique (la lutte contre le sexisme est tout aussi importante que la lutte contre le racisme ou I'homophobie), politique (cette lutte se concrétise par un engagement formel des pouvoirs publics) et éducative (les discussions aident à la prise de conscience collective)." J. Charruau, entrevistado por Mallaval (2017).
} 
preventiva que punitiva. Tal y como apunta García-Pablos de Molina (1992, p. 96), "prevenir significa intervenir en la etiología del problema criminal, neutralizando sus causas. Contramotivando al delincuente (con la amenaza de la pena, o con un sistema legal en excelente estado de funcionamiento) quedan aquéllas intactas, no se atacan las raíces del problema sino sus síntomas o manifestaciones. Lo que no basta". En este sentido, como ya se ha dicho, la educación parece ser la mejor solución para terminar con las discriminaciones y con cualquier forma de acoso. "La educación sensibiliza en valores de igualdad y de respeto mutuo entre niñas y niños desde la más tierna edad, y de ello depende la construcción de una sociedad en la que el reconocimiento y el respeto de la dignidad de la persona y la absoluta prohibición de las afrentas al prójimo sean los pilares fundamentales" (Secretaría de Estado francés 2018, p. 26). ${ }^{21}$

\section{Referencias}

Barrère Unzueta, M., 2013. El acoso sexual: una mirada a sus orígenes y a su evolución en la unión europea. En: J.M. Gil Ruiz, ed., Acoso sexual y acoso por razón de sexo: actuación de las administraciones públicas y de las empresas [en línea]. Barcelona: Generalitat de Catalunya / Centre d'Estudis J urídics i Formació Especialitzada, pp. 17-50. Disponible en: https://www. ehu. eus/documents/2007376/0/Acoso+sexual+y+acoso+por +ra z\%C3\%B3n+de+sexo [Con acceso el 19 de septiembre de 2019].

Bodelón, E., 2014. Las violencias sexuales en las universidades: cuando lo que no se denuncia no existe. Revista Española de Investigación Criminológica [en línea], no 12, artículo 1. Disponible en: https://dialnet.unirioja.es/descarga/articulo/4783305.pdf [Con acceso el 19 de septiembre de 2019].

Bowman, C., 1993. Street Harassment and the Informal Ghettoization of Women. Harvard Law Review [en línea], 106(3), pp. 517-580. Disponible en: https://doi.org/10.2307/1341656 [Con acceso el 26 de abril de 2019].

Brooks, C., 1995. Passing By: Gender and Public Harassment. Oakland: University of California Press.

Brooks, L., 2018. UK police chiefs urged to adopt harassment of women as hate crime. The Guardian [en línea], 9 de julio. Disponible en:

https://www.theguardian.com/world/2018/jul/09/uk-police-chiefs-urged-toadopt-harassment-of-women-as-hate [Con acceso el 26 de abril de 2019].

Calvo, M., 2014. Capítulo IV. La violencia de género como violación de Derechos Humanos. El papel de los movimientos sociales en la lucha por los derechos. En: F.J . Ansuátegi Roig et al., eds., Historia de los Derechos Fundamentales, vol. 4, t. V, Libro I. Madrid: Dykinson.

Calvo, M., 2016. The Role of Social Movements in the Recognition of Gender Violence as a Violation of Human Rights: From Legal Reform to the Language of Rights. The Age of Human Rights Journal [en línea], no 6, pp. 60-82. Disponible en: https://doi.org/10.17561/tahr].v0i6.2930 [Con acceso el 3 de julio de 2019].

Charruau, J., 2015. Une loi contre le sexisme? Étude de l'initiative belge. La Revue des droits de l'Homme [en línea], $\mathrm{n}$ o 7. Disponible en: http://journals.openedition.org/revdh/1130 [Con acceso el 3 de julio de 2019].

Clavaud, A., Finchelstein, G., y Kraus, F., 2018. Les femmes face aux violences sexuelles et le harcèlement dans la rue [en línea]. Estudio realizado para la Fundación J ean Jaurès y la Fundación europea de estudios progresistas.

\footnotetext{
${ }^{21}$ Todas las traducciones al castellano que aparecen en el presente artículo son obra de la autora.
} 
Fondation Jean Jaurès, 19 de noviembre. Disponible en: https://jeanjaures.org/nos-productions/les-femmes-face-aux-violences-sexuelles-et-leharcelement-dans-la-rue [Con acceso el 3 de julio de 2019].

Condon, S., Lieber, M., y Maillochon, F., 2005. “Insécurité dans les espaces publics: comprendre les peurs féminines", Revue française de sociologie [en línea], 46(2), pp. 265-294. Disponible en : https://doi.org/10.3917/rfs.462.0265 [Con acceso el 3 de julio de 2019].

Darsonville, A., 2017. Brèves remarques sur le projet de loi contre les violences sexistes et sexuelles. AJ pénal, № 12, pp. 532-534.

Daza Bonachela, M.M., 2012. La intervención del orden penal como medida disuasoria. En: M.M. Daza Bonachela et al., eds., Las medidas disuasorias frente al acoso sexual y por razón de sexo. Madrid: Dykinson, p. 79.

Denizot, A., y Mallet-Bricout, B., 2018. Une loi inapplicable est-elle une loi inutile? RTD Civ. Chroniques Législation française, № 4, pp. 980-983.

El País, 2019. Harvey Weinstein. El País [en línea]. Disponible en: https://elpais.com/tag/harvey_weinstein/a [Con acceso el 3 de julio de 2019].

Farley, L., 1978. Sexual Shakedown: The Sexual Harassment of Women on the Job. Nueva York: McGraw-Hill.

Femme de la Rue, 2012 [en línea]. Reportaje. Dirigido por Sofie Peeters. Disponible en: https://www.dailymotion.com/video/x3fb4sp [Con acceso el 19 de septiembre de 2019].

García-Pablos de Molina, A., 1992. La prevención del delito en un estado social y democrático de derecho. Estudios Penales y Criminológicos [en línea], XV(Cursos e Congresos, $\mathrm{n}$ - 71). Disponible en:

http://hdl.handle.net/10347/4193 [Con acceso el 19 de septiembre de 2019].

Gil Ruiz, J., 2013. Introducción. En: J.M. Gil Ruiz, ed., Acoso sexual y acoso por razón de sexo: Actuación de las administraciones públicas y de las empresas [en línea]. Barcelona: Generalitat de Catalunya / Centre d'Estudis J urídics i Formació Especialitzada, pp. 11-16. Disponible en: https://www. ehu.eus/documents/2007376/0/Acoso+sexual+y+acoso+por +ra z\%C3\%B3n+de+sexo [Con acceso el 19 de septiembre de 2019].

JUMP, 2016. Informe Sexisme, bientôt fini? [en línea]. Bruselas. Disponible en: https://jump.eu.com/wp-content/uploads/2016/11/Full_Report-SexismeFrench_Englishweb.pdf [Con acceso el 3 de julio de 2019].

Junta de Andalucía, 2017. \#NoSeasAnimal [en línea]. Campaña. Disponible en: http://faunacallejera.com/ [Con acceso el 26 de abril de 2019].

Lamarca Pérez, C., 2010. Delitos contra la libertad e indemnidad sexuales. En: C. Lamarca Pérez, ed, Derecho Penal: parte especial. 5a ed. Madrid: Colex, p. 165.

Larrauri Pijoán, E., 1997. El nuevo delito de acoso sexual: Una primera valoración. Cuadernos de Derecho Judicial [en línea], no 7. Disponible en: http://www. cienciaspenales. net/files/2016/09/1el-nuevo-delito-de-acososexual.-una-primera-valoracion-elena-larrauri.pdf [Con acceso el 19 de septiembre de 2019].

Lebugle, A., 2017. Les violences dans les espaces publics touchent surtout les jeunes femmes des grandes villes. Population et Sociétés [en línea], n 550 . Disponible en: https://doi.org/10.3917/popsoc.550.0001 [Con acceso el 3 de julio de 2019].

Lieber, M., 2002. Le sentiment d'insécurité des femmes dans l'espace public: une entrave à la citoyenneté? Nouvelles Questions Féministes [en línea], 21(1), 
pp. 41-56. Disponible en: https://doi.org/10.3917/nqf.211.0041 [Con acceso el 3 de julio de 2019].

Mallaval, C., 2017. En Belgique, une loi imitée aux effets limités. Libération [en línea], 6 de diciembre. Disponible en:

https://www. liberation.fr/france/2017/12/06/en-belgique-une-loi-imitee-auxeffets-limites_1614964 [Con acceso el 3 de julio de 2019].

Ministerio francés de Interior, 2018. Insécurité et délinquance en 2017 : premier bilan statistique [en línea]. Encuesta. 24 de enero. Disponible en: https://www.interieur.gouv. fr/Interstats/Actualites/Insecurite-et-delinquanceen-2017-premier-bilan-statistique [Con acceso el 26 de abril de 2019].

Ministerio francés de Justicia, 2018. Présentation de la loi $n^{\circ} 2018-703$ du 3 août 2018 renforçant la lutte contre les violences sexuelles et sexistes (CRIM/201810/H2-03.09.2018) [en línea]. Circular. 3 de septiembre. Disponible en: http://www.justice.gouv.fr/bo/2018/20180928/]USD1823892C.pdf [Con acceso el 3 de julio de 2019].

Ministerio francés del Interior, 2015. Plan national de lutte contre le harcèlement sexiste et les violences sexuelles [en línea]. Julio. Disponible en: https://www.gouvernement. fr/sites/default/files/action/piecejointe/2015/07/plan-national-de-lutte-contre-le-harcelement-sexiste-et-lesviolences-sexuelles-dans-les-transports-en-commun.pdf [Con acceso el 3 de julio de 2019].

ONU Mujeres, 2014. Informe Iniciativa mundial Ciudades Seguras [en línea]. Nueva York: Naciones Unidas. Disponible en: http://www. aecid.es/CentroDocumentacion/Documentos/Divulgaci\%C3\%B3n/En\%20pocas\%20palabras.p df [Con acceso el 3 de julio de 2019].

Planque, J.C., 2017. Ne créez pas le délit d'outrage sexiste! Juris-Classeur Périodique, La semaine du droit, 1314.

RATP, 2018. Campagne de lutte contre le harcèlement dans les transports "Ne minimisons jamais le harcèlement sexuel" [en línea]. Nota de prensa. 3 de abril. Disponible en: https://www.ratp.fr/grouperatp/newsroom/securite/campagne-de-lutte-contre-le-harcelement-dans-lestransports-ne [Con acceso el 20 de septiembre de 2019].

Rivas Vallejo, M.P., y García Valverde, M., eds., 2015. Tratamiento integral del acoso. Cizur Menor: Thomson Reuters Aranzadi.

Rubio Castro, A., 2013. La regulación del acoso sexual y del acoso por razón de sexo en la legislación española. En: J.M. Gil Ruiz, ed., Acoso sexual y acoso por razón de sexo: actuación de las administraciones públicas y de las empresas [en línea]. Barcelona: Generalitat de Catalunya / Centre d'Estudis Jurídics i Formació Especialitzada, p. 52 y ss. Disponible en: https://www. ehu. eus/documents/2007376/0/Acoso+sexual+y+acoso+por +ra z\%C3\%B3n+de+sexo [Con acceso el 19 de septiembre de 2019].

Saas, C., 2018. Harcèlement de rue ou le droit à être dans l'espace public. Gazette du Palais, no 16, p. 81.

Saguy, A., 2000. Employment Discrimination or Sexual Violence? Defining Sexual Harassment in American and French Law. Law \& Society Review [en línea], 34(4), 1091-1128. Disponible en: https://doi.org/10.2307/3115132 [Con acceso el 3 de julio de 2019].

Secretaría de Estado español de Igualdad, 2017. Pacto de Estado en Materia de Violencia de Género [en línea]. Documento refundido. Disponible en: http://www. violenciagenero. igualdad.mpr.gob.es/pactoEstado/docs/Document o_refundido_PEVG_pdf [Con acceso el 3 de julio de 2019]. 
Secretaría de Estado francés, 2018. Rapport du groupe de travail "verbalisation du harcèlement de rue" [en línea]. Informe. 28 de febrero. Disponible en:

https://www. egalite-femmes-hommes.gouv.fr/rapport-du-groupe-de-travailverbalisation-du-harcelement-de-rue [Con acceso el 3 de julio de 2019].

Siegel, R., 2003. A Short History of Sexual Harassment [en línea]. En: C.A. MacKinnon y R.B. Siegel, eds., Directions in Sexual Harassment Law. New Haven, CT: Yale University Press. Disponible en: https://doi.org/10.12987/yale/9780300098006.003.0001 [Con acceso el 3 de julio de 2019].

Tapia Ballesteros, P., 2016. El nuevo delito de acoso o stalking. Barcelona: Wolters Kluwer.

Tellier-Cayrol, V., 2018. Réflexions sur la contravention d'outrage sexiste. Dalloz Actualité [en línea], 14 de mayo. Disponible en: https://www. dallozactualite.fr/chronique/reflexions-sur-contravention-d-outragesexiste\#.XEGm8vx7nfY [Con acceso el 3 de julio de 2019].

Thompson, D., 1993. The Woman in the Street: Reclaiming the Public Space from Sexual Harassment. Yale J ournal of Law \& Feminism [en línea], 6(2), Art. 4. Disponible en: http://digitalcommons.law.yale. edu/yjlf/vol6/iss2/4 consultado el 3 de julio de 2018.

Vandekerkhove, C., 2018. Première en Belgique: un homme condamné pour sexisme dans l'espace public. BFMTV [en línea], 6 de marzo. Disponible en: https://www.bfmtv.com/societe/premiere-en-belgique-un-homme-condamnepour-sexisme-dans-I-espace-public-1389278.html [Con acceso el 19 de septiembre de 2019].

Vicente, Á., 2018. Cien artistas e intelectuales francesas contra el "puritanismo" sexual. El País [en línea], 10 de enero. Disponible en: https://elpais.com/cultura/2018/01/09/actualidad/1515513768_647890.html [Con acceso el 3 de julio de 2019].

Ximenez, P., 2018. MeToo año 1: cómo las mujeres perdieron el miedo. El País [en línea], 5 de octubre. Disponible en: https://elpais.com/sociedad/2018/10/04/actualidad/1538678547_217451.htm I [Con acceso el 3 de julio de 2019].

Referencias normativas

Bélgica

Loi tendant à lutter contre le sexisme dans l'espace public et modifiant la loi du 10 mai 2007 tendant à lutter contre la discrimination entre les femmes et les hommes afin de pénaliser l'acte de discrimination. Moniteur belge [en línea] no 55452, de 24 de julio de 2014. Disponible en: https://igvmiefh. belgium.be/sites/default/files/downloads/22_mai_2014. loi tendant_a_lutter_contre_le_sexisme.pdf [Con acceso el 26 de abril de $\overline{201 \overline{9}] \text {. }}$

España

Artículo 172.ter del Código penal español. Ley Orgánica 1/2015 de 30 de marzo, por la que se modifica la Ley Orgánica 10/1995, de 23 de noviembre, del Código penal. Boletín Oficial del Estado [en línea], no 77, de 31 de marzo de 2017. Disponible en: https://www.boe. es/buscar/act.php?id=BOE-A-199525444\&tn $=1 \& p=20190302 \#$ a172 [Con acceso el 26 de abril de 2019].

Artículo 184 del Código Penal español. Se modifica por el art. único.66 de la Ley Orgánica 15/2003, de 25 de noviembre. Boletín Oficial del Estado [en línea], no 283 , de 26 de noviembre de 2003, páginas 41842 a 41875 . Disponible en: 
https://www. boe.es/buscar/act.php?id=BOE-A-1995-

25444\&tn=1\&p=20190302\#a184 [Con acceso el 26 de abril de 2019].

Instrumento de ratificación del Convenio del Consejo de Europa sobre prevención y lucha contra la violencia contra la mujer y la violencia doméstica, hecho en Estambul el 11 de mayo de 2011. Boletín Oficial del Estado [en línea], no 137, de 6 de junio de 2014, páginas 42946 a 42976 . Disponible en:

https://www.boe.es/diario_boe/txt.php?id=BOE-A-2014-5947 [Con acceso el 26 de abril de 2019].

Ley Orgánica 3/2007 para la Igualdad Efectiva entre hombres y mujeres. Boletín Oficial del Estado [en línea], no 71, de 23 de marzo de 2007. Disponible en: https://www. boe.es/buscar/act.php?id=BOE-A-2007-6115 [Con acceso el 26 de abril de 2019].

Proposición de Ley no 122/000279 de Protección Integral de la Libertad Sexual y para la Erradicación de las Violencias Sexuales. Boletín Oficial de las Cortes Generales [en línea], № 318-1, de 15 de octubre de 2018. Disponible en: http://www.congreso.es/public_oficiales/L12/CONG/BOCG/D/BOCG-12-D519.PDF [Con acceso el 26 de abril de 2019].

Francia

Art. 21, Código procesal penal francés [en línea]. Disponible en: https://www.legifrance.gouv.fr/affichCodeArticle.do?cidTexte=LEGITEXT00000 6071154\&idArticle=LEGIARTI000006574886\&dateTexte $=\&$ categorieLien $=c i d$ [Con acceso el 26 de abril de 2019].

Art. L2241-1, Código francés de los transportes [en línea]. Disponible en: https://www. legifrance. gouv.fr/affichCode.do; jsessionid=CA719E94EB49EBA7 0863168B526063C3.tplgfr28s 1?idSectionTA=LEGISCTA000023084161\&cidTe $\underline{x t e}=$ LEGITEXT000023086525\&dateTexte $=20190521$ [Con acceso el 26 de abril de 2019].

Arts. 222-33, Código penal francés [en línea]. Disponible en: https://www. legifrance.gouv.fr/affichCode.do?idSectionTA=LEGISCTA0000217 96946\&cidTexte=LEGITEXT000006070719 [Con acceso el 26 de abril de 2019].

Asamblea Nacional francesa, 2018. Etude d'impact. Projet de loi renforçant la lutte contre les violences sexuelles et sexistes NOR : JUSD1805895L/Bleue- 1 [en línea]. 19 de marzo. Disponible en: http://www.assembleenationale.fr/15/projets/pl0778-ei.asp [Con acceso el 3 de julio de 2019].

Loi $n$ 2018-703 renforçant la lutte contre les violences sexuelles et sexistes (JUSD1805895L). Journal officiel de la République française [en línea], no 0179, de 5 de agosto de 2019. Disponible en:

https: // www. legifrance. gouv.fr/affichLoiPubliee. do; jsessionid=14AA6D4C01A4 0E17E187CFD93D575FA6.tplgfr29s 3?idDocument=J ORFDOLE000036730730 \&type $=$ contenu\&id=2\&typeLoi=\&legislature $=15$ [Con acceso el 26 de abril de 2019].

Nuevo art. 621-1 del Código penal francés [en línea]. Disponible en:

https://www. legifrance. gouv.fr/affichCode.do; jsessionid=44ABA3F50B304D53 D09A499665E99ACA.tplgfr29s 3?idSectionTA=LEGISCTA000037287954\&cidT exte $=$ LEGITEXT000006070719\&dateTexte $=20190918$ [Con acceso el 26 de abril de 2019].

Portugal

Lei n. 0 83/2015, de 5 de agosto. Trigésima oitava alteração ao Código Penal, aprovado pelo Decreto-Lei n. $.400 / 82$, de 23 de setembro, autonomizando o crime de mutilação genital feminina, criando os crimes de perseguição e 
casamento forçado e alterando os crimes de violação, coação sexual e importunação sexual, em cumprimento do disposto na Convenção de Istambul [en línea]. Disponible en:

http://www.pgdlisboa.pt/leis/lei_mostra_articulado.php?nid=2381\&tabela=leis \&ficha=1\&pagina $=1 \&$ so miolo [Con acceso el 3 de julio de 2019]. 